\title{
Muscle Pathology in Polymyalgia Rheumatica: Histochemical and Immunohistochemical Study
}

\author{
Susumu KoJIMA, Akio TAKAGI, Masayoshi IDA and Ryouichi SHIOZAWA
}

\begin{abstract}
Immunohistochemical studies were performed on muscle biopsy specimens of polymyalgia rheumatica (PMR) to evaluate the extent of muscle and peripheral nerve involvement. The routine histochemistry revealed a mild variation of fiber size, type 2 fiber atrophy and type $2 A$ or $2 B$ fiber deficiency. In $63 \%$ of the PMR cases small angular fibers, pyknotic nuclear clumps or target-targetoid fibers were observed, suggesting neurogenic changes, although abnormalities were mild in degree. In immunocytochemical studies, neither major histocompatibility complex (MHC) class 1 nor class 2 products were expressed on the muscle surface membrane of PMR. But regarding intramuscular vessels, MHC class 2 products were distinctly visualized. On serial sections, combined deposits of IgG and Clq in perimysial arteries were seen in $38 \%$ of PMR.

These results suggest that arteries of small caliber might be involved in immunopathological processes, causing muscle and peripheral nerve damage.
\end{abstract}

Key words: Temporal arteritis, Vasculitis, Major histocompatibility complex, Immune complexes, Neuropathy, Immunohistochemistry

Polymyalgia rheumatica (PMR) is a clinical syndrome which was originally described by Barber in 1957 (1). Although myalgia is the cardinal feature of PMR, little is known about the muscle pathology. The close relationship between PMR and temporal arteritis (TA) has been documented $(2,3)$. The precise nature of this association remains unknown, but some investigators have suggested that PMR is a manifestation of arteritis (4). The evidence of vasculitis is lacking in muscle biopsy specimens of $\operatorname{PMR}(5,6)$. To date there seem to be few immunological analyses on affected muscle tissue of PMR.

Recently, the association of TA/PMR and neuropathy has been reported $(7,8)$. Ultrastructural examination of the skeletal muscle in PMR suggests that a neurogenic mechanism play a pathogenetic role (9). But histological and histochemical examinations have revealed little evidence of neurogenic changes $(5,10)$.

In the present study, we examined muscle biopsy specimens of PMR histochemically and immunocytochemically to determine the mechanism of muscle and nerve involvement.

\section{MATERIALS AND METHODS}

Muscle specimens were obtained from 11 cases of PMR, 12 polymyositis (PM), 4 dermatomyositis (DM), 1 polyarteritis nodosa (PN), and 9 cases of disease control (4 cases of motor neuron disease, 3 entrapment neuropathy, 2 myotonic muscular dystrophy) and 2 normal controls. In each instance, biopsy was performed after informed consent was ascertained. Diagnosis of PMR was made according to the criteria of Bird et al (11), and also the new criteria proposed in Japan (12). Only 2 of 11 patients with PMR complained of headache. None of the patients with PMR had visual symptoms, tenderness over the temporal artery or jaw claudication. A biopsy of the temporal artery was not performed in any case. All patients with PM

From Department of Neurology, Toranomon Hospital, Tokyo

Received for publication April 19, 1990; Accepted for publication February 7, 1991

Reprint requests should be addressed to Susumu Kojima, MD, Department of Neurology,

Kawasaki Branch of Toranomon Hospital, 1-3-1 Kajigaya, Takatsu-ku, Kawasaki 213, Japan

This study was supported in part by grant(62-2A) from NCNP of the Ministry of Health and Welfare, Japan 
and DM met 3 or 4 of the criteria of Bohan and Peter (13). None of the PMR patients had received steroid therapy prior to biopsy. Clinical data of patients with PMR are summarized in Table 1. Data of blood analyses and electrophysiological studies are described in the results section.

Biopsied muscle specimens were mounted and frozen in isopentane cooled by liquid nitrogen. Muscle sections were $10 \mu \mathrm{m}$ thick for routine histochemistry and $6 \mu \mathrm{m}$ thick for immunohistochemistry. For the immunoperoxidase method, muscle sections were dried in air, washed three times in phosphate-buffered saline (PBS, $\mathrm{pH}$ 7.2) for 10 min, fixed with cooled acetone for $5 \mathrm{~min}$, and incubated in a moist chamber for 30 to $60 \mathrm{~min}$ with various primary antibodies listed on Table 2 . Antisera to human IgG, IgM, IgA or albumin were peroxidase conjugated. Products of these reactions were visualized with diaminobenzidine (DAB) and $0.01 \%$ hydrogen peroxide in PBS. For other antibodies, we used Biotin-Streptoavidin kit (BioGenex Laboratories, San Ramon) to visualize final products. To test specificity of reactions, control rabbit or mouse serum or PBS was used in place of primary antibodies. To avoid nonspecific binding of secondary antibodies to Fc receptors, we used the $\mathrm{F}(\mathrm{ab}$ ') fragment of antibodies conjugated to peroxidase.

Statistical analysis was carried out according to $\chi^{2}$ test or Fisher's exact probability test.

Table 1. Clinical Data of Patients with Polymyalgia Rheumatica

\begin{tabular}{|c|c|c|c|c|c|c|c|c|c|c|c|c|c|c|c|c|}
\hline & & $\begin{array}{l}\text { Positive No. } \\
\text { of Bird's } \\
\text { criteria }\end{array}$ & $\begin{array}{l}\text { ESR } \\
(\mathrm{mm} / \mathrm{h})\end{array}$ & CRP & $\begin{array}{c}\text { RF(Rose) } \\
(\mathrm{U} / \mathrm{ml})\end{array}$ & ANF & $\begin{array}{c}\text { anti-DNA } \\
\text { ENA,RNP,Sm }\end{array}$ & $\begin{array}{c}\mathrm{CK} \\
(\mathrm{IU} / \mathrm{I})\end{array}$ & $\begin{array}{c}\lg G \\
(\mathrm{mg} / \mathrm{dl})\end{array}$ & IgA & IgM & $\operatorname{IgE}$ & $\begin{array}{c}\mathrm{CH} 50 \\
(\mathrm{U})\end{array}$ & $\begin{array}{l}\mathrm{C} 3 / \mathrm{C} 4 \\
(\mathrm{mg} / \mathrm{dl})\end{array}$ & $\underset{\mu \mathrm{g}(\mathrm{ml})}{\mathrm{IC}}$ & $\mathrm{T} 4 / \mathrm{T} 8$ \\
\hline $1^{*}$ & $M / 61$ & $4 / 7$ & 103 & $9+$ & $+(<16)$ & - & - & 121 & 1,565 & $\underline{275}$ & 139 & 398 & 80 & $\underline{140 / 49}$ & nd & nd \\
\hline $2^{*}$ & $M / 79$ & $6 / 7$ & 80 & $9+$ & 6 & - & - & 75 & 2,313 & $\overline{453}$ & 498 & $\overline{42}$ & $\overline{\text { nd }}$ & $94 / 28$ & nd & 1.69 \\
\hline 3 & $\mathrm{~F} / 70$ & $4 / 7$ & 113 & $5+$ & 15 & - & - & 32 & $\overline{2,472}$ & $\overline{724}$ & $\overrightarrow{123}$ & 72 & 72 & $99 / 36$ & 1.8 & nd \\
\hline 4 & $\mathrm{~F} / 61$ & $5 / 7$ & 85 & $2+$ & 12 & - & - & 45 & nd & $\overline{\text { nd }}$ & nd & nd & $\overline{\mathrm{nd}}$ & $\mathrm{nd} / \mathrm{nd}$ & 3.5 & $\underline{2.53}$ \\
\hline 5 & $F / 73$ & $6 / 7$ & 55 & $9+$ & $\overline{11}$ & $1: 80(\mathrm{H})$ & - & 385 & 921 & 274 & 38 & 124 & nd & $\mathrm{nd} / \mathrm{nd}$ & $\overline{\text { nd }}$ & $\overline{\text { nd }}$ \\
\hline 6 & $\mathrm{~F} / 69$ & $5 / 7$ & 113 & $6+$ & 8 & $1: 320(\mathrm{H})$ & - & 35 & 1,530 & 222 & 222 & 66 & 68 & $69 / 31$ & $<1.5$ & nd \\
\hline 7 & $\mathrm{M} / 71$ & $4 / 7$ & 62 & $4+$ & 8 & nd & nd & 43 & 1,690 & 266 & 105 & 290 & 76 & $\underline{101 / 39}$ & nd & 1.18 \\
\hline 8 & $F / 51$ & $5 / 7$ & 70 & - & 9 & - & - & 47 & 1,750 & 407 & 68 & nd & $\overline{45}$ & $66 / 9$ & 3.7 & 2.10 \\
\hline 9 & $F / 66$ & $6 / 7$ & 52 & $3+$ & $\underline{11}$ & - & - & 38 & 1,902 & 290 & 159 & 732 & $\underline{61}$ & $76 / \underline{43}$ & $\overline{\text { nd }}$ & $\underline{0.94}$ \\
\hline 10 & $\mathrm{M} / 71$ & $6 / 7$ & 52 & $7+$ & 9 & - & - & 41 & 1,880 & 275 & 149 & 312 & $\underline{64}$ & $\underline{105} / \overline{43}$ & nd & 4.50 \\
\hline 11 & $\mathrm{~F} / 50$ & $5 / 7$ & 64 & $3+$ & 9 & $1: 40(\mathrm{H})$ & - & 90 & nd & nd & nd & nd & 60 & $\overline{90} / \overline{28}$ & nd & $\overline{2.10}$ \\
\hline (Nor & & & & & $(0-10)$ & & & $(<150)$ & $(820-2,290)$ & $(130-380)$ & $(60-380)$ & $(<350)$ & $(40 \pm 10)$ & $9-81)(9-35)$ & $(<3.0)$ & $(1.8 \pm$ \\
\hline
\end{tabular}

* Immunocytochemistry was not analyzed

M, male; F, female; No., number; ESR, erythrocyte sedimentation rate; CRP, C-reactive protein; RF, rheumatoid factor; ANF, anti-nuclear factor; ENA, extractable nuclear antigen; RNP, ribo-nucleoprotein; IC, immune complexes; nd, not determined

Table 2. Monoclonal and Polyclonal Antibodies Used in this Study

\begin{tabular}{lll}
\hline Cell type or antigen & \multicolumn{1}{c}{ Antibody } & \multicolumn{1}{c}{ Source } \\
\hline HLA-A,B,C. & W6/32 (monoclonal) & Sera-lab \\
HLA-DR & L243 (monoclonal) & Becton Dickinson \\
T cytotoxic/suppressor cell (CD8) & anti-Leu-2A (monoclonal) & Becton Dickinson \\
T helper/inducer cell (CD4) & anti-Leu-3a (monoclonal) & Becton Dickinson \\
B cell (CD 19) & anti-Leu-12 (monoclonal) & Becton Dickinson \\
C9 & anti-C9 (polyclonal) & Wako \\
Clq & anti-Clq (polyclonal) & Dakopatts \\
Ig G & anti-IgG $\gamma$ chain (polyclonal; F(ab')) & Dakopatts \\
Ig M & anti-IgM $\mu$ chain (polyclonal; F(ab')) & Dakopatts \\
Ig A & anti-IgA $\alpha$ chain (polyclonal; F(ab')) & Dakopatts \\
\hline
\end{tabular}




\section{RESULTS}

Histological and histochemical findings (Fig. 1)

In PMR, there were mild myogenic changes: a mild variation of fiber size with a few necrotic or regenerating fibers, and fibers with internal nuclei (Fig. 2). Intramuscular vessels appeared normal on hematoxylin and eosin (HE) stain. In $63 \%$ of PMR cases, neuropathic features such as small angular fibers $(6 / 11)$, target or targetoid fibers $(1 / 11)$, pyknotic nuclear clumps (3/11), and small group atrophy $(1 / 11)$ were observed.

Regarding the muscle fiber type abnormalities, type 2 fiber atrophy was observed in $81 \%(9 / 11)$ [type $2 \mathrm{~A}$ atrophy in $27 \%(3 / 11)$, type $2 \mathrm{~B}$ atrophy in $45 \%(5 / 11)$, both type $2 \mathrm{~A}$ and $2 \mathrm{~B}$ atrophy in $9 \%$ $(1 / 11)]$ and fiber type deficiency was seen in $45 \%$ $(5 / 11)$ [type $2 \mathrm{~A}$ deficiency in $18 \%(2 / 11), 2 \mathrm{~B}$ deficiency in $36 \%(3 / 11)$ ]. The fiber type grouping was seen only in two patients $(18 \%)$ and to a very

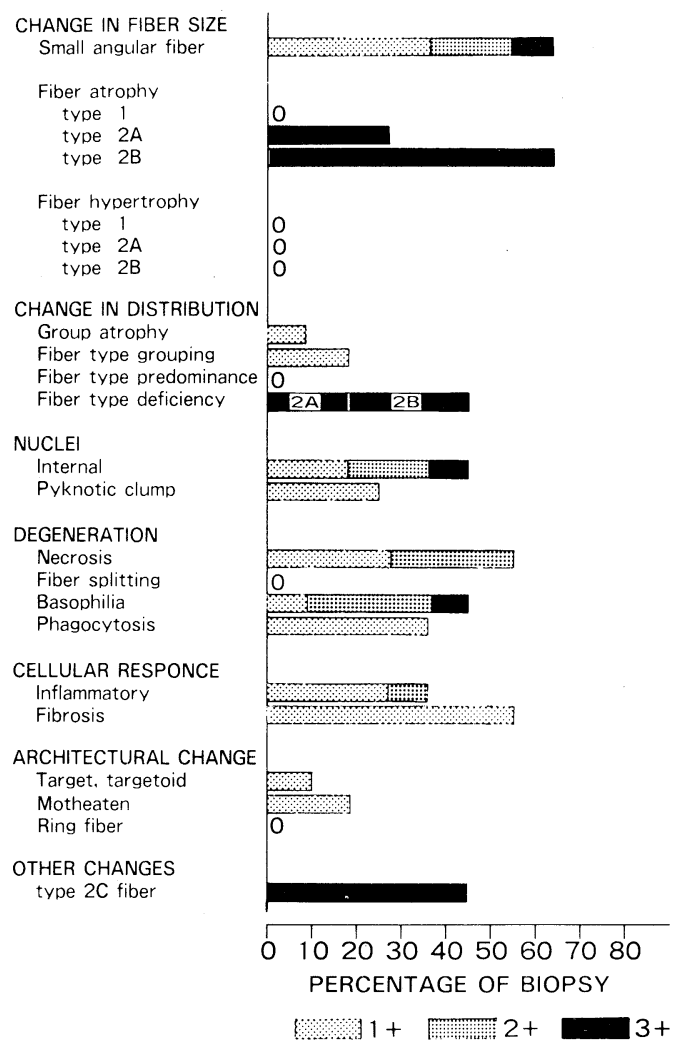

Fig. 1. Summary of histological and histochemical findings of polymyalgia rheumatica. mild in degree.

\section{Immunocytochemical findings}

Neither MHC class 1 nor class 2 products were expressed on the sarcolemma of PMR and controls. In contrast, MHC class 1 and class 2 products on the sarcolemma were observed in $63 \%$ and $56 \%$ of PM-DM, respectively (Fig. 3). In the blood vessel walls (presumably in endothelial cells), MHC class 2 products were stained more strongly in PMR than in controls and PM-DM (Fig. 4).

Deposition of $\operatorname{IgG}, \operatorname{IgM}$ and $\operatorname{IgA}$, alone or in combination, was detected on the sarcolemma and in the intramuscular vessel wall of PMR, PM-DM, and controls. Although the specimens were washed extensively with PBS before fixation with cooled acetone, there were a few deposits of immunoglobulin, complement and albumin even in normal control specimens. Thus, we considered it abnormal when staining was clearly more than in controls. Deposition of IgM was more frequent in the sarcolemma of PMR than in that of PM-DM and disease controls $(p<0.05)$.

On serial muscle sections, the association of IgG and Clq in the intramuscular vessel wall was seen in three out of eight cases of PMR (Fig. 5), three out of 11 of PM-DM, and one case of PN. There was no such association in controls. In one case of PM-DM, association of IgG, IgM and Clq was detected. In another case of PM-DM, combination of IgM and Clq was seen. In PMR, vessels with immunoglobulin and complement staining were 50-200 $\mu \mathrm{m}$ in diameter, and they were usually located in the perimysial area. No vessels in the endomysial area, many of which were considered to be capillaries, were stained with immunoglobulin or complement in PMR. The staining of C9 was significantly more frequent in PM-DM than in PMR and disease controls $(p<0.05)$. Clq was also stained more frequently in vessels of both PMR and PM-DM than in those of disease controls $(p<0.05)$. Sections incubated with control mouse or rabbit serum or PBS were negative for staining of immunoglobulin or complements.

A few mononuclear cells were seen in the endomysium or perivascular area of PMR. The majority of those cells were acid phosphatase positive and were classified as macrophages. 

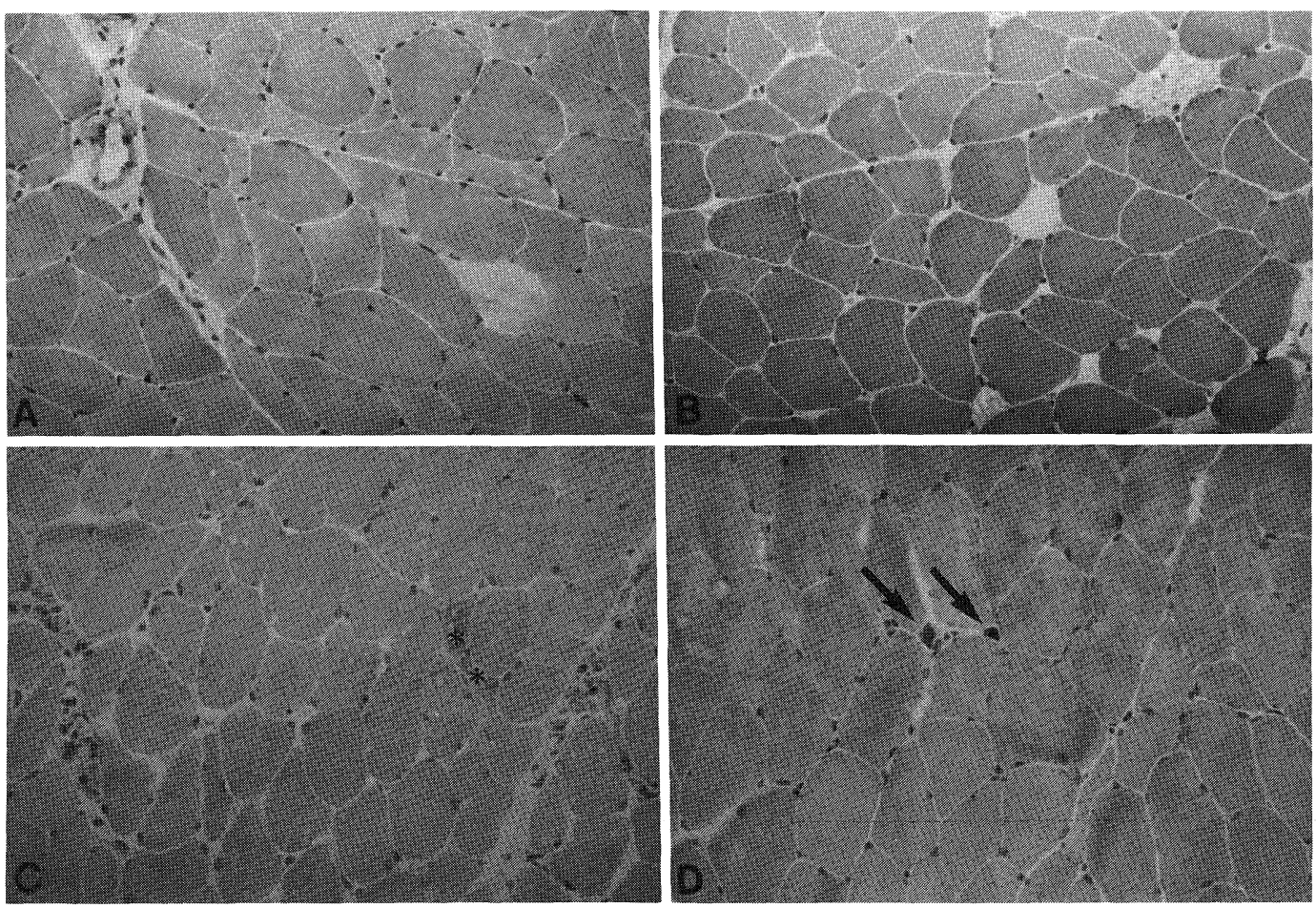

Fig. 2. Polymyalgia rheumatica showing a slight variation of fiber size with a few necrotic (A, B) or regenerating (basophilic) fibers (C; asterisk). Fibers with internal nuclei (A) are few. Nuclear clumps (D; arrows) are seen amongst normal looking fibers. Hematoxylin and eosin (HE) stain; $\times 200$.

Endomysial Leu 2a (cytotoxic/suppressor), Leu 3a (helper/inducer) positive $\mathrm{T}$ cells and perivascular Leu 12 positive (B) cells were rarely observed.

\section{Other clinical data of PMR (Table 1)}

Erythrocyte sediment rate (ESR) and $C$ reactive protein (CRP) were increased in each case of PMR. Increased IgG, IgA, IgM and IgE was seen in 22 (2/9), 33 (3/9), 11 (1/9) and in 25\% (2/8) of PMR patients, respectively. Creatine kinase (CK) activities in serum were normal except in one case. The concentration of $\mathrm{CK}$ in this case (case 5) had returned to normal before the start of steroid therapy.

Study of $\mathrm{T}$ lymphocyte subsets showed an increased ratio of $\mathrm{T} 4 / \mathrm{T} 8$ in $50 \%(2 / 4)$ and a decreased ratio in $25 \%(1 / 4)$. Immune complexes were detected in $50 \%(2 / 4)$. Increased level of $\mathrm{CH} 50, \mathrm{C} 3$ or $\mathrm{C} 4$ was observed in $83 \%$ of cases $(5 / 6), 67 \%(6 / 9)$ or $56 \%(5 / 9)$, respectively. Rheumatoid factors were raised in $45 \%(5 / 11)$ of cases, but to a very mild degree. Antinuclear antibodies were also weakly positive in $30 \%(3 / 10)$, but none of the cases had antibodies to deoxyribonucleic acid (DNA) or to extractable nuclear antigens (ENA).

Sensory or motor nerve conduction velocity was measured in nine cases of PMR. In seven out of nine cases $(78 \%)$, the nerve conduction velocity was slightly reduced. Electromyography was also abnormal in eight out of 11 cases (73\%): mild myopathic changes $4 / 11(36 \%)$, mild neuropathic $2 / 11(18 \%)$, both mild myopathic and neuropathic $2 / 11(18 \%)$.

\section{DISCUSSION}

Recent immunohistochemical studies have shown that class 1 or class 2 products of major histocompatibility complex (MHC) are expressed on muscle fibers in inflammatory myopathy or in other neuromuscular disorders (14-16). If the skeletal muscle of PMR is a target of the immunopatho- 

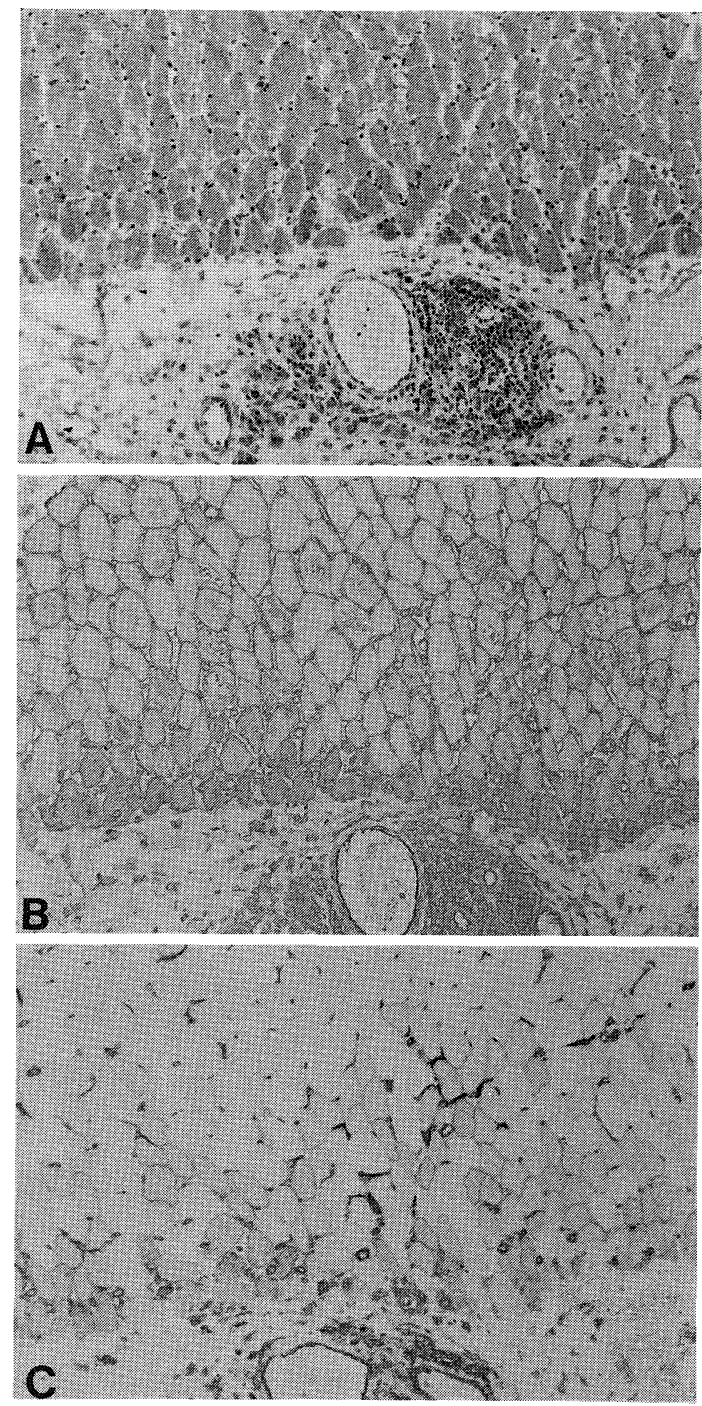

Fig. 3. Serial sections from a case of dermatomyositis. (A) There are prominent mononuclear cells in perimysial areas. Necrotic and phagocytic fibers can also be seen. (B) MHC class I products are expressed on almost all muscle fibers; some muscle fibers also show cytoplasmic staining. (C) MHC class II staining is limited to the fibers near the perimysium and to those in the vicinity of mononuclear cells. $\times 200$.

logical process, those products might be expressed on the sarcolemma. We demonstrated this was not the case in PMR, although MHC class 1 and class 2 products were observed on the muscle of PM-DM by the same procedure.
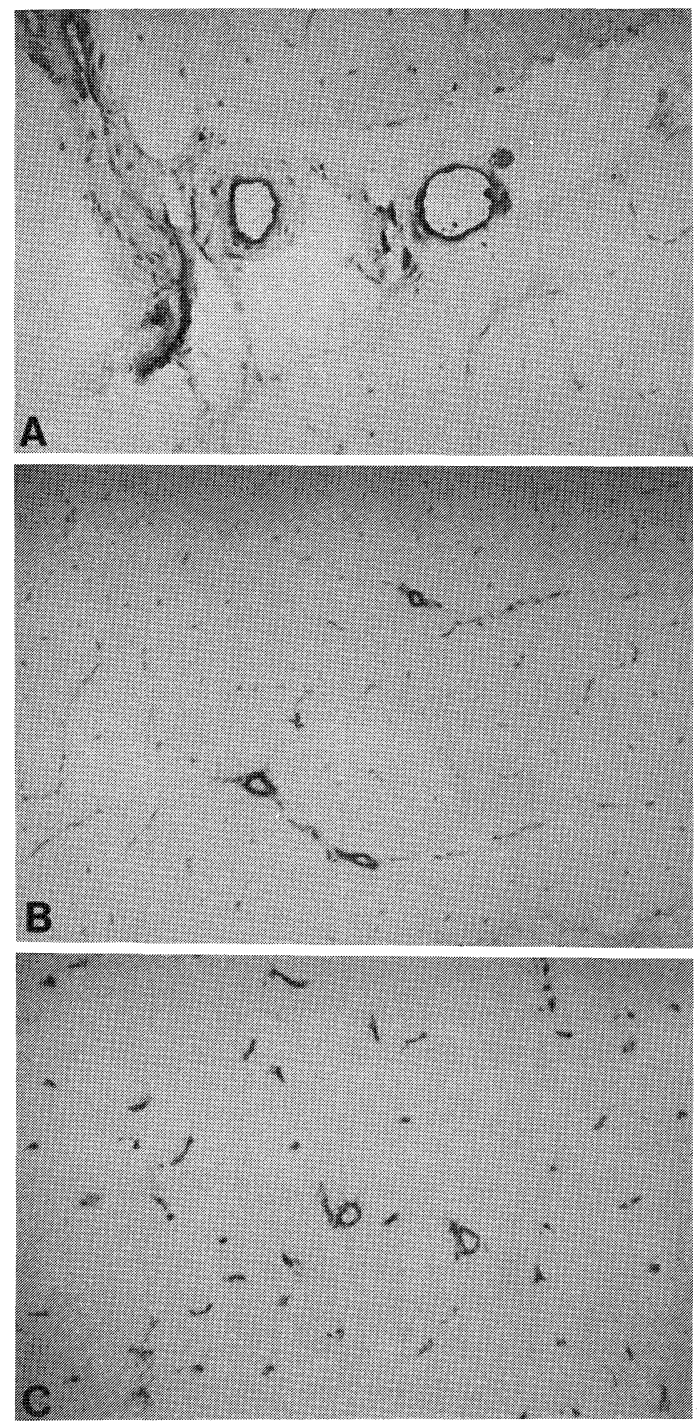

Fig. 4. Immunohistochemistry of HLA-DR. HLA-DR expression is more marked in intramuscular vessels of polymyalgia rheumatica $(\mathrm{A}, \mathrm{B})$ than in those of motor neuron disease $(C) . \times 200$.

Cell-mediated cytotoxity has been considered to play a major role in the pathogenesis of PM-DM $(17,18)$. The present results suggested that the muscle cell itself is not a target of MHC restricted $\mathrm{T}$ cells in PMR. Many previous studies and the present results showed that there are abnormal subpopulations of $\mathrm{T}$ cells in the peripheral blood of PMR $(19,20)$. This abnormality might be related 

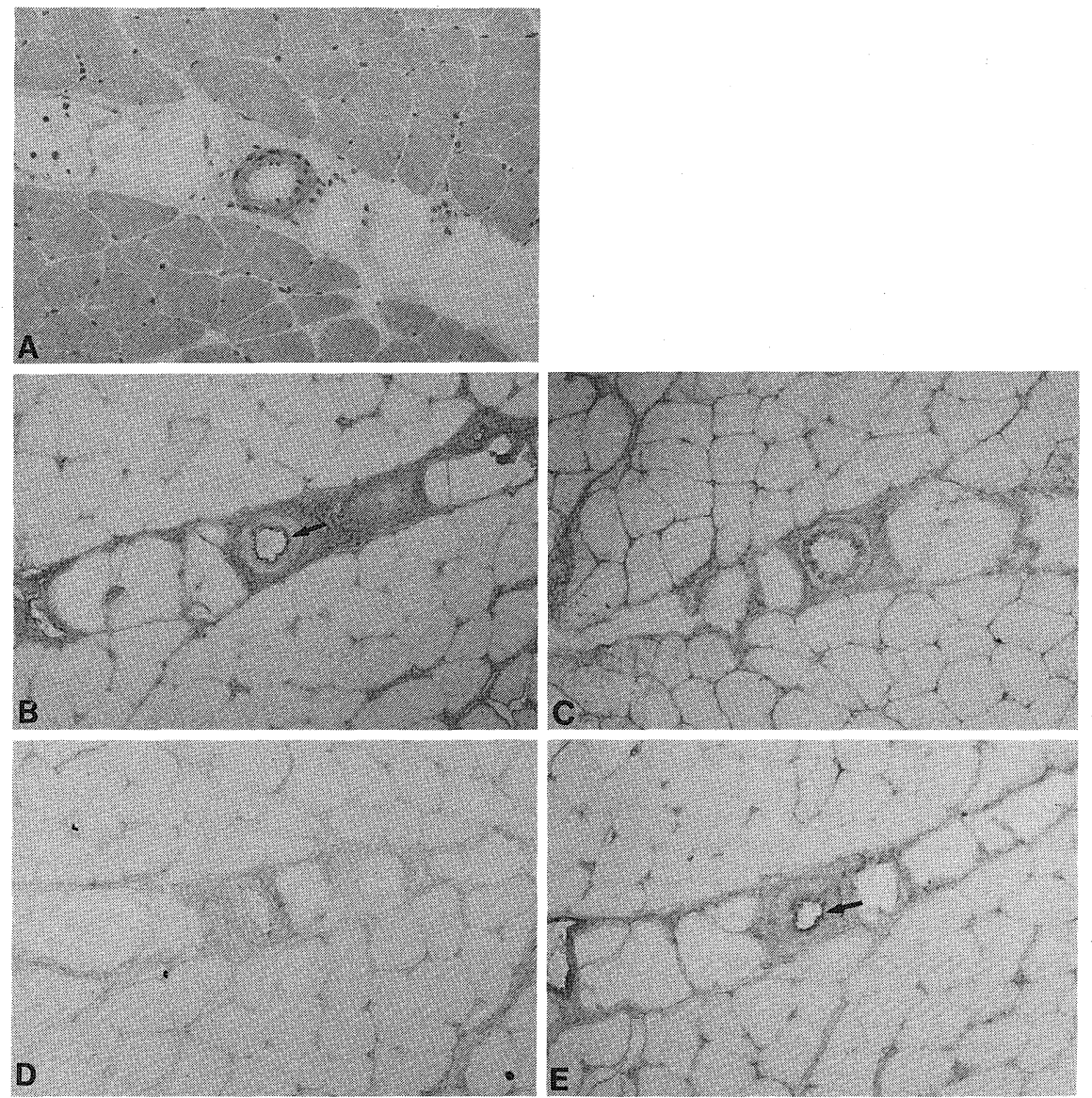

Fig. 5. Serial sections from a case of polymyalgia rheumatica stained with HE (A), immunostaining for IgG (B), IgM (C), IgA (D) or Clq (E). Arrows indicate the deposition of $\operatorname{IgG}(\mathrm{B})$ and Clq (E). $\times 200$.

to vascular pathology rather than to muscle injury, since more distinct deposition of MHC class 2 products and combined deposits of $\mathrm{IgG}$ and $\mathrm{Clq}$ were occasionally detected in the intramuscular vessels.

The IgG and Clq deposition in intramuscular vessels of PMR could indicate the presence of immune complexes, since sera from patients with TA or PMR contained increased levels of immune complexes (21). And in some cases of temporal arteritis, immunoglobulin and complement deposits have been demonstrated in biopsied temporal arteries $(22,23)$. An electron microscopic study of synovium in PMR also revealed microvascular changes, suggesting the existence of immune com- plexes (24). These reports are consistent with present results, implicating a pathogenetic role of immune complexes in PMR, although some authors indicated a lack of specificity of these deposition, which suggests the possibility of a non-specific reaction to muscle injury (25-28). In TA, involved arteries were mainly large ones that directly branched from the aortic arch. The diameter of vessels, where the immunoglobulin and complement deposition was demonstrated, was small and ranged between 50 and $200 \mu \mathrm{m}$. If the caliber of involved arteries differs in TA and PMR, the difference might be attributed to the size of immune complexes (29).

Histochemical and electrophysiological findings have indicated involvement of peripheral nerve in 
PMR. However, the clinical significance of neuropathy was obscure. The vascular involvement, which was demonstrated in the skeletal muscle of PMR, could also cause neuropathy. On the other hand, neuropathy in PMR could be coincidental, since patients with PMR are generally of old age. Further pathologic study of the peripheral nerve is necessary on this point.

Every case of PMR in this study fulfilled the two different diagnostic criteria $(11,12)$, and none showed symptoms which suggest other collagen diseases. All patients with PMR also showed prompt and favorable early response to the steroid therapy. Thirty percent of our cases, however, indicated weakly positive antinuclear antibodies and $45 \%$ of the cases had mildly raised rheumatoid factors. In PMR, antinuclear antibodies and rheumatoid factors have been considered to be generally negative (12). The pathogenetic significance of antinuclear antibodies or rheumatoid factors in PMR would be a matter of further study.

In conclusion, the present study suggests that muscle and peripheral nerve manifestations in PMR is caused by vascular involvement of small vessels, which is induced by immune complexes.

ACKNOWLEDGMENTS: The authors acknowledge the skillful assistance of Seiko Tsutsumi and Hiromi Soeda for histochemistry analyses, and Taeko Honda for manuscript preparation.

\section{REFERENCES}

1) Barber HS. Myalgic syndrome with constitutional effects. Polymyalgia rheumatica. Ann Rheum Dis 16: 230, 1957.

2) Alestig K, Barr J. Giant cell arteritis: A biopsy study of polymyalgia rheumatica, including one case of Takayasu's disease. Lancet 1: 228, 1963.

3) Fauchald P, Rygvold O, Oystese B. Temporal arteritis and polymyalgia rheumatica. Clinical and biopsy findings. Ann Intern Med 77: 845, 1972.

4) Paulley JW, Hughes JP. Giant cell arteritis or arteritis of the aged. Br Med J 2: 1562, 1960.

5) Brooke $\mathrm{MH}$, Kaplan H. Muscle pathology in rheumatoid arthritis, polymyalgia rheumatica, and polymyositis. A histochemical study. Arch Pathol 94: $101,1972$.

6) Jerusalem F. Circulatory disorders and pathology of intramuscular blood vessels. in: Skeletal Muscle Pathology, Mastaglia FL, Sir Walton J, Eds. Churchill
Livingston, Edinburgh, 1982, p.537.

7) Nesher G, Rosenberg P, Shorer Z, Gilai A, Solomonovich A, Sonnenblick M. Involvement of the peripheral nervous system in temporal arteritispolymyalgia rheumatica. Reports of 3 cases and review of literature. J Rheumatol 14: 2, 1987.

8) Caselli RJ, Daube JR, Hunder GG, Whisnant JP. Peripheral neuropathic syndromes in giant cell (temporal) arteritis. Neurology 38: 685, 1988.

9) Fassbender R, Simmling-Annefeld M. Ultrastructural examination of the skeletal muscles in polymyalgia rheumatica. J Pathol 137: 181, 1982.

10) Isaacs H, Frere G. Non-specific arthralgia and myalgia with subclinical neuropathy. A histochemical and histological study. S Afr Med J 47: 1581, 1973.

11) Bird HA, Esselinckx W, Dixon ASJ, Mowat AG, Wood PHN. An evaluation criteria for polymyalgia rheumatica. Ann Rheum Dis 38: 434, 1979.

12) Kaneoka H, Yamaguchi $M$, Matsui $Y$, Nagayoshi $T$, Ohta A. Thirteen cases of polymyalgia rheumatica: their diagnosis and the association with HLA system. Jpn J Clin Immunol 9: 20, 1986.

13) Bohan A, Peter JB. Polymyositis and dermatomyositis (first of two parts). N Engl J Med 292: 344, 1975.

14) Appleyard ST, Dunn MJ, Duvowitz V, Rose ML. Increased expression of HLA ABC class 1 antigen by muscle fibers in Duchenne muscular dystrophy, inflammatory myopathy, and other neuromuscular disorders. Lancet 2: 361, 1985.

15) Karpati G, Pouliot Y, Carpenter S. Expression of immunoreactive major histocompatibility complex products in human skeletal muscles. Ann Neurol 23: 64, 1988.

16) McDounall RM, Dunn MJ, Dubowitz V. Expression of class I and class II MHC antigens in neuromuscular diseases. J Neurol Sci 89: 213, 1989.

17) Dawkins RL, Mastaglia FL. Cell-mediated cytotoxity to muscle in polymyositis. N Engl J Med 288: 434, 1981.

18) Engel AG, Arahata K. Monoclonal antibody analysis of mononuclear cells in myopathies. II: Phenotypes of autoinvasive cells in polymyositis and inclusion body myositis. Ann Neurol 16: 209, 1984.

19) Benlahrache $C$, Segond $P$, Auquier L, Bouvet J. Decrease of the OKT8 positive $T$ cell subset in polymyalgia rheumatica. Lack of correlation with disease activity. Arthritis Rheum 26: 1472, 1983.

20) Elling $H$, Elling P. Decreased level of suppressor/ cytotoxic $\mathrm{T}$ cells $(\mathrm{OKT} 8+)$ in polymyalgia rheumatica and temporal arteritis: Relation to disease activity. J Rheumatol 12: 2, 1985.

21) Papaioannou CC, Gupta RC, Hunder GG, Mcduffie FC. Circulating immune complexes in giant cell arteritis and polymyalgia rheumatica. Arthritis Rheum 23: 1021, 1980.

22) Liang GC, Simkin PA, Mannik M. Immunoglobulins in temporal arteries. An immunofluorescent study. Ann Intern Med 81: 19, 1974.

23) Waaler E, Tonder O, Milde E-J. Immunological and 
histological studies of temporal arteries from patients with temporal arteritis and/or polymyalgia rheumatica. Acta Pathol Microbiol Scand, Sect A 84: 55, 1976.

24) Chou C-T, Schumacher HR Jr. Clinical and pathologic studies of synovitis in polymyalgia rheumatica. Arthritis Rheum 27: 1107, 1984.

25) Isenberg DA. Immunoglobulin deposition in skeletal muscle in primary muscle disease. Q J Med 52: 297, 1983.

26) Whitaker JN, Engel WK. Vascular deposits of immunoglobulin and complement in idiopathic inflammatory myopathy. N Engl J Med 286: 333, 1972.

27) Oxenhandler R, Adelstein EH, Hart MN. Immunopathology of skeletal muscle. The value of direct immunofluorescence in the diagnosis of connective tissue disease. Human Pathol 8: 321, 1977.

28) Cohn RA, Mauer SM, Barbosa J, Michael AF. Immunofluorescence studies of skeletal muscle extracellular membranes in diabetes mellitus. Lab Invest 39: 13, 1978.

29) Van Es LA. Factors affecting the deposition of immune complexes. Clin Immunol Allergy 1: 281, 1981. 